\title{
Ultrasonographic Examination of The Forelimb Joint Regions in Normal 1- To 2-Month-Old Holstein Calves
}

\author{
Ronan JJ Chapuis ${ }^{1}$, Nora Cesbron ${ }^{2}$, Claude Guintard ${ }^{3}$ and Marion Fusellier ${ }^{4 *}$ \\ ${ }^{1}$ Ross University School of Veterinary Medicine, West Indies \\ ${ }^{2}$ Department of Farm Animal, College of Veterinary Medicine, France \\ ${ }^{3}$ Department of Anatomy, Nantes-Atlantic National College of Veterinary Medicine, France \\ ${ }^{4}$ Department of Diagnostic Imaging, Nantes-Atlantic National College of Veterinary Medicine, France
}

\begin{abstract}
Many studies have described the normal and pathologic ultrasonographic appearance of the musculoskeletal system in cattle. However, these previous studies present few images and descriptions of the aspect of this system in calves. The aim of this anatomic study was to describe the normal ultrasonographic examination of the forelimb joints in 1- to 2-month-old Holstein calves, as well as to present the techniques used to acquire the images. The joint regions of the forelimbs of four cadaver calves were studied. Six forelimbs were evaluated by ultrasonography using a 13.0 MHz linear transducer. The images acquired were compared with those acquired with other imaging techniques (six forelimbs were x-rayed, three forelimbs were scanned using magnetic resonance imaging (MRI)) and compared with anatomical pieces (one forelimb was dissected, four forelimbs were frozen and sectioned for frozen slides) to finally label the different structures visualized on ultrasonographic pictures. The soft tissues, cartilaginous structures and bone surfaces showed similar echogenicity to what has been previously described. All the anatomical structures were successfully imaged and identified except for the vascular structures due to the post-mortem aspect of the study. To the authors' knowledge, this study is the first to provide an exhaustive description of the normal appearance of forelimb joints of the Holstein calf using multi-modal imaging techniques. The purpose of this study was to provide a reference when determining the presence of pathological joint disease of the forelimbs of calves.
\end{abstract}

KEYWORDS: Ultrasonography; Forelimb; Thoracic limb; Calves; Joint; Anatomy

\section{INTRODUCTION}

In equine medicine, the advantage of ultrasound for studying the locomotor apparatus has already been demonstrated [1]. In cattle, the usefulness of ultrasonographic evaluation in cases of musculoskeletal disorders is also well established, although it is less widespread. It is recognized to be part of the diagnostic approach in cases of suspected musculoskeletal disease, such as during the evaluation of damaged soft tissue $[2,3,4,5]$. The increased interest in the use of this diagnostic tool in calves has led to the recent publication of reports describing its use in several areas, such as cardiac, pulmonary and abdominal diseases $[6,7,2]$.
Quick Response Code:

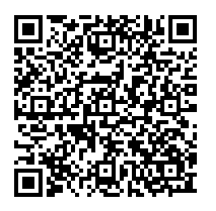

Address for correspondence: Marion Fusellier, Department of Diagnostic Imaging, Nantes-Atlantic National College of Veterinary Medicine, Food Science and Engineering (ONIRIS), France

Received: December 08, 2019 Published: February 04, 2020

How to cite this article: Ronan JJ C, Nora C, Claude G, Marion F. Ultrasonographic Examination of The Forelimb Joint Regions in Normal 1- To 2-Month-Old Holstein Calves. 2020 - 2(1) OAJBS.ID.000137. DOI: 10.38125/OAJBS.000137 
It has been shown in human medicine that joint ultrasonography can detect pathological changes prior to the manifestation of clinical and radiographic signs [8]. It can indeed detect very slight changes, making the ultrasonographic examination a very sensitive test to detect lesions within joints $[8,9,3,4,10]$.

Ultrasonography has started to be more widely available to field practitioners and internists in bovine hospitals [11,12]. In this context, more studies are needed "on the diagnostic and prognostic use of ultrasound in ruminants" [13].

Arthritis is the second most common cause of lameness in cattle [14], causing significant economic loss [15]. In young animals, arthritis commonly arises secondary to hematogenous spread from distant sites of infection, such as infected umbilicus, pneumonia or intestinal translocation [14]. Arthritis diagnosis is made based on clinical examination and the results of ancillary diagnostic tests. Radiographs give principally prognostic information $[3,4]$ because the lesions are not visible before 1-3 weeks $[14,3]$. In addition, the exact location and extent of the lesions are usually not diagnosed [3]. Cytology and culture require lab time before results are obtained and the puncture of the joint. They do not allow early diagnosis and risk joint contamination. Ultrasound is more sensitive than radiography $[9,3,10]$ in assessing the extent of the synovial distension, the presence of cartilage or periarticular lesions, and detecting the presence of fibrin. This technique can provide enough information to reach a diagnosis and institute appropriate therapy [14].

Arthritis often requires a long period of healing despite appropriate therapies and usually carries a poor prognosis. Delaying the initiation of treatment worsens the prognosis [14-17]. Therefore, earlier detection of a joint infection can lead to a better outcome. Since the duration of arthritis treatment is empirical, [14] the development of decisional criteria to initiate or pursue a treatment could improve the management of arthritis on farms. For economic reasons and to avoid unnecessary pain in incurable animals, ultrasonographic examination seems promising [10].

Normal musculoskeletal and joint ultrasonography of cattle is clearly described in the literature $[18,4]$. Of the publications describing the forelimb, a significant number of them are written in French, German, Portuguese or Spanish, and therefore not available to English-speaking practitioners [18-24]. In the Englishlanguage publications, which focus on adult cattle, few images have been presented or described for calves [3-5,11,17,25-32]. A recent publication aimed to describe the distal limbs of 8-to 12-monthold Nellore and Girolando calves [33]. However, to our knowledge a thorough description of the normal ultrasonographic appearance of the musculoskeletal apparatus in calves less than 2 months old is still lacking.

To generate accurate images, the sonograph operators must be aware of the anatomic landmarks in order to place the probe correctly; they must also be familiar with the normal appearance of the area studied in order to detect pathological changes [17]. To pursue studies on the ultrasonographic aspects of joint diseases in calves and to provide practitioners with a tool for accurate diagnosis on the farm, it appears necessary to describe the normal ultrasonographic appearance of joints in the calf and the techniques that allow proper image acquisition.

In the initial work [34-38], the objective was to present the ultrasonographic images acquired from a portable unit equipped with a $7.5 \mathrm{MHz}$ transducer and those from a console style unit equipped with a $13 \mathrm{MHz}$ transducer. The images were presented as an atlas with descriptions for probe placement. In addition, the radiographs, MRI images, and pictures of the anatomic pieces of the region studied were presented to help the reader understand the location and orientation of the images.

The purpose of this article is to describe the techniques for transducer placement on calf joints, to produce correctly orientated imaging planes with a console style unit equipped with a $13.0 \mathrm{MHz}$ linear transducer and to present the acquired images with labels.

\section{MATERIALS AND METHODS}

All procedures for this anatomic study were conducted at NantesAtlantic National College of Veterinary Medicine, Food Science and Engineering (Oniris). Eight forelimbs from three Holstein male calves and one Holstein heifer with a mean of age of 32 days (range: 18-53 days) and a mean of weight of $41 \mathrm{~kg}$ (range: $31-57 \mathrm{~kg}$ ) were selected for the study. The calves were hospitalized in the Oniris Clinics for Ruminants, appropriated for teaching purposes and then euthanized. The calves had no history of musculoskeletal diseases, umbilical disorders, diarrhea, respiratory disorders or sepsis. No invasive procedures were performed in the teaching hospital. Prior to euthanasia, complete physical examinations were performed, and vital parameters were confirmed to be within normal values. All joints were closely examined and no evidence of joint swelling, joint deformities, lameness, pain, skin abrasions or scars were noted.

The front limbs were anatomically detached from the thorax. The skin of the shoulder region was extended and sutured medially to maintain the physiological soft tissue tightness of the shoulder.

The data were acquired in multiple steps. For the ultrasonographic examinations, two ultrasound machines were used to assess whether images could be acquired in the field or in the hospital. First, a mobile ultrasound machine (IME520 Vet of IMEDSYS $®$ unit equipped with a 7.5-MHz rectal linear transducer) was used on six forelimbs. Secondly, to maximize the resolution and improve image quality, a different ultrasound machine (Technos MP of ESAOTE $®$, Genova, Italy) equipped with a 13.0-MHz linear transducer was used on four forelimbs. All ultrasound images were acquired in B-mode. The joint areas were shaved and cleaned with alcohol, and an ultrasonic gel was applied prior to acquiring the images. The limbs were examined on a table in a horizontal position. An acoustic stand-off (silicone) was used from the carpus to the most distal part of the limb to enhance the contact. All images were recorded such that the cranial, dorsal, medial or proximal aspect of the limb appeared on the left of the console's screen. Cutaneous sutures were placed during the ultrasonographic examination to precisely identify the position of the transducer.

Four limbs were then frozen such that the joint angulation was in the same position during the ultrasound data acquisition. Sectional planes were made at the same plane as the ultrasound beam plane. The limbs were sectioned with a band saw, at the level of the sutures, with a plane like the ultrasound beam's orientation used for the ultrasound image acquisitions. Pictures of the frozen slides were taken.

MRI scans (MAGNETOM Harmony 1.0T ND of Siemens ${ }^{\circledR}$, Germany) of the joints were produced on three limbs. The sutures made it possible to identify where the ultrasound examinations were performed. 
Six limbs were radiographed on lateromedial and craniocaudal views (computed radiography, Convix $300 \mathrm{HF} 50 \mathrm{~kW}$, Picker ${ }^{\circledR}$ with numeric plates ERLM, Fujifilm $®)$. Finally, the structure studied was dissected on one limb.

All ultrasonographic images were compared and labelled in accordance with the dissection, the radiographic images, the corresponding frozen anatomic sections, the MRI and anatomic atlases [35-38]. The imaging data were viewed with the OsiriXv.2.7.5 software and labelled with Adobe Photoshop CS3 software. All the images were reviewed by a radiologist (Dr. Marion Fusellier) and an anatomist (Dr. Claude Guintard) from the Oniris teaching hospital.

\section{RESULTS}

\section{Tissue Echogenicity}

All bone surfaces showed a linear homogenous hyperechoic structure producing an acoustic shadow. The articular cartilage covering the hyperechoic bone was identified as a regular thin to thick anechoic layer with homogenously distributed echoic spots. The ossification center and the large distal cartilaginous

\section{Shoulder or Scapulohumeral Joint (Articulatio Humeri [39]) (Figure 1-5)}
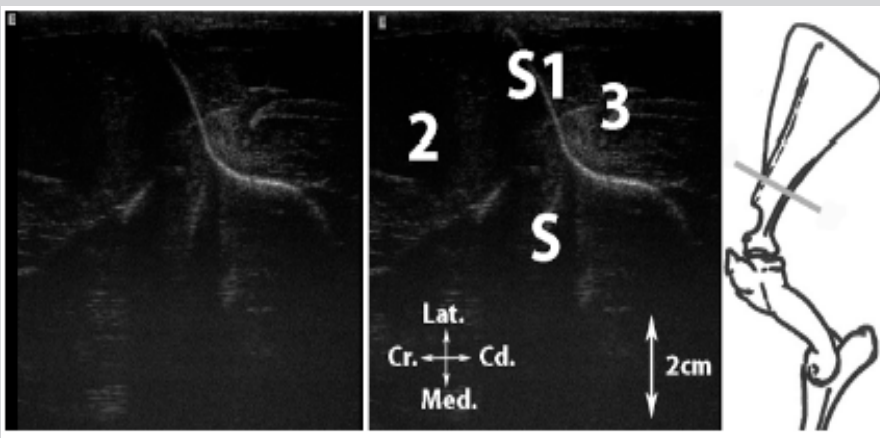

Figure 1: Transversal scan of the scapular spine (Spina scapulae).

Legend: S: scapula, S1: scapular spine (Spina scapulae), 2: supraspinatus m., 3: infraspinatus m.
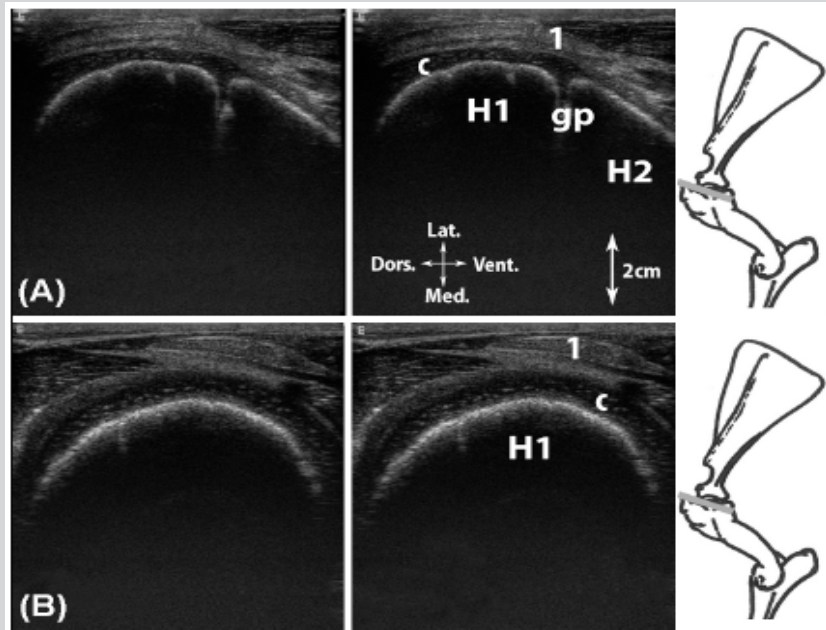

Figure 2: A, Transversal scan of the infraspinatus $m$. tendon at the level of the humeral growth plate; $B$, Transversal scan of the infraspinatus $m$. tendon.

Legend: $\mathrm{H} 1$ : greater tubercle of the humerus (Tuberculum majus), H2: humerus, c: articular cartilage, gp: cartilaginous growth cartilage, 1: infraspinatus $m$. tendon. 
Five regions of interest were scanned and described. The bone surface of the scapula, the scapular spine (spina scapulae [39]), the greater and lesser tubercles of the humerus (tuberculum majus and minus [39]), the humeral head (caput humeri [39]), the articular cartilage, the humeral proximal growth cartilage plates and the ossification center of the greater and lesser tubercles, the supraspinatus $m$., the infraspinatus $m$. and its tendon, the biceps brachii tendon and the joint space were clearly identified. The scapular spine was localized by digital palpation. On the lateral aspect of the joint, the greater tubercle of the humerus was palpable. The transducer was applied transversely to the scapular spine. The supra- and infraspinatus mm. were imaged on each side of the spine (Figure 1). The transducer was moved distally to reach the lateral joint area. The transverse view of the tendon of the infraspinatus $m$. was imaged laterally to the greater tubercle of the humerus, which was covered by a thick layer of cartilage. This view showed the cartilaginous growth plate on the proximal aspect of the humerus (Figure 2). The transducer was then turned 90 degrees and moved ventrally to image the tendon longitudinally and reach its insertion on the greater tubercle of the humerus. The growth plate localized between the humeral head and the greater tubercle of the humerus was imaged (Figure 3). To study the cranial part of the joint, the transducer was kept in the same position and the palpation of the intertubercular groove (sulcus intertubercularis [39]) assisted its placement. The biceps brachii $\mathrm{m}$. tendon was imaged on the longitudinal view. Part of the tendon ran on the ossification center of the humeral tubercles, shown as a cartilaginous hypoechoic structure. The growth cartilage between the humeral head and the greater tubercle was imaged. The transducer was moved dorsally to ventrally and the entire part of the tendon was studied in this region (Figure 4). The transducer was then rotated 90 degrees to obtain the transverse view of the tendon running in the intertubercular groove. The growth cartilages between the greater tubercle and the humeral head, as well as between the greater and the lesser tubercles were imaged. These views allowed us to differentiate the two ossification centers more easily, which were characterized by the cartilaginous echogenicity of the greater and lesser tubercles, which formed the intertubercular groove (Figure 5).
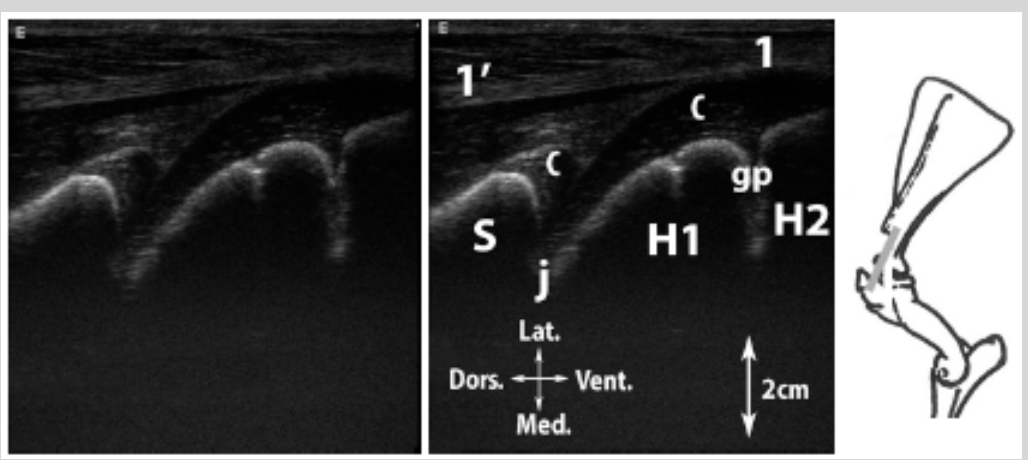

Figure 3: Longitudinal scan of the infraspinatus $m$. tendon.

Legend: H1: humeral head (Caput humeri), H2: greater tubercle of the humerus, S: ventral angle of the scapula (Angulus ventralis), c: articular cartilage, gp: cartilaginous growth plate, j: scapulohumeral joint (Articulatio humeri), 1 : infraspinatus $m$. tendon, 1 ': infraspinatus $m$.
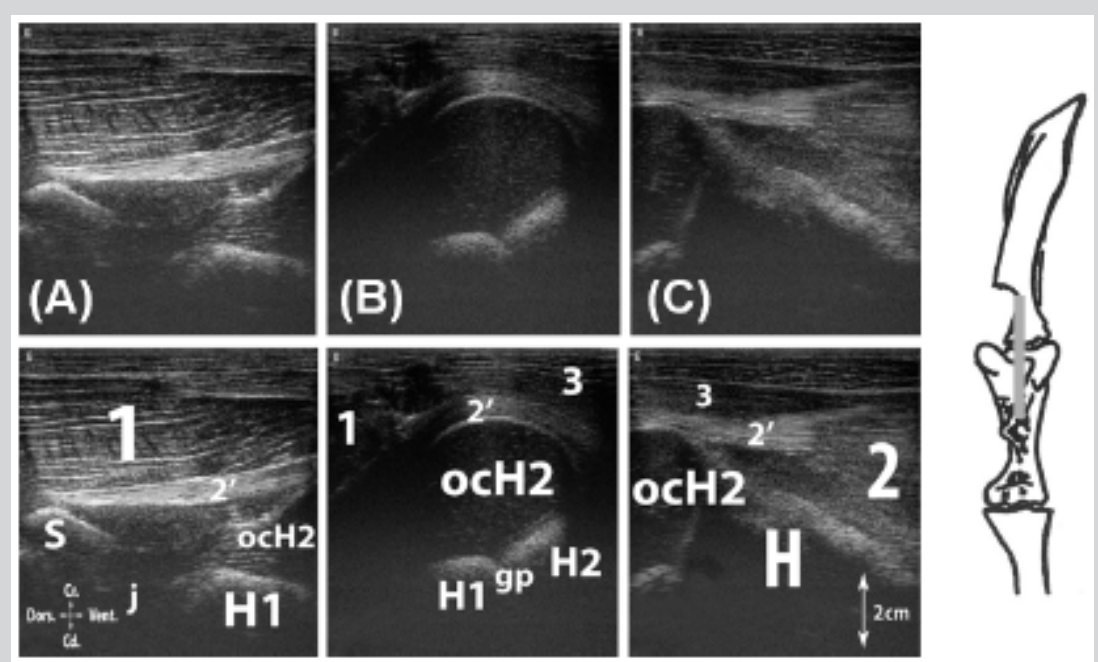

Figure 4: Longitudinal scan of the biceps brachii $\mathrm{m}$. tendon. $\mathrm{A}$, at the level of the intertubercular groove; $\mathrm{B}$, at the level of the major humeral tubercle; $C$, ventral to the major humeral tubercle.

Legend: $\mathrm{H}$ : humerus, $\mathrm{H} 1$ : humeral head, $\mathrm{H} 2$ : greater tubercle of the humerus, ocH2: ossification center of the greater tubercle of the humerus, S: supraglenoid tubercle (Tuberculum supraglenoidale), j: scapulohumeral joint, 1: supraspinatus m., 2: biceps brachii m., 2': biceps brachii m. tendon, 3: deep pectoral m. (M. pectoralis profundus). 

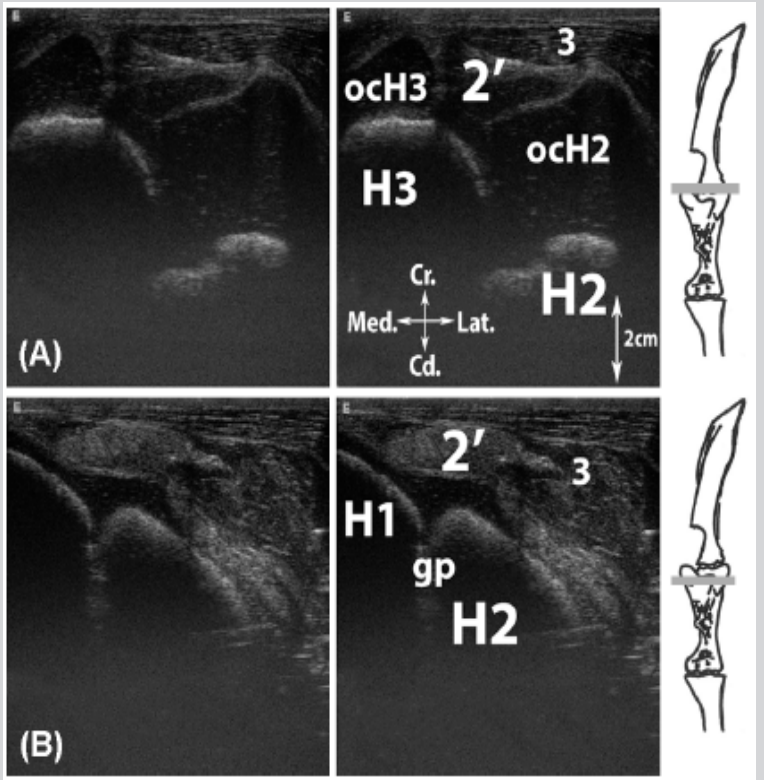

Figure 5: Transversal scan of the biceps brachii tendon. A, dorsal to major humeral tubercle; $B$, at the level of the major humeral tubercle.

Legend: $\mathrm{H1}$ : humeral head, H2: greater tubercle of the humerus, H3: lesser tubercle of the humerus (Tuberculum minus), ocH2: ossification center of the greater tubercle of the humerus, ocH3: ossification center of the lesser tubercle of the humerus, gp: cartilaginous growth plate, 2': biceps brachii $\mathrm{m}$. tendon, 3: deep pectoral $\mathrm{m}$.

\section{Elbow Joint (Articulatio Cubiti [39]) (Figure 6,7)}

Two regions of interest were scanned and described. The bone surface of the humerus and radius, the joint space, the articular cartilage, the distal humeral and the proximal radial growth cartilage plates, the lateral collateral ligament (Lig. collaterale cubiti laterale [39]), the medial (caput accessorium m. extensor digitorum communis [39]) and common digital extensor (M. extensor digitorum communis [39]) proximal enthesis and the belly of the extensor carpi radialis $\mathrm{m}$. were identified. The landmark was located by palpating the humeral lateral epicondyle (epicondylus lateralis [39]) and the lateral aspect of the head of the radius (caput radii [39]). The transducer was positioned at this level, parallel to the radius axis in order to study the lateral collateral ligament of the joint, the distal humeral cartilaginous growth plate and the proximal radial cartilaginous growth plate (Figure 6). On the cranial aspect of the joint, the belly of the extensor carpi radialis $\mathrm{m}$. was palpable. The transducer was applied on the muscle, parallel to the axis of the radius, and moved dorsally until the joint space was visible on the screen. Both cartilaginous growth plates were identified. The tendinous insertion of the medial and common digital extensor $\mathrm{mm}$. was composed with a considerable amount of connective tissue characterized by a homogenous mild echogenicity. The bellies of the medial and the common digital extensor mm. were seen between the joint area and the belly of the extensor carpi radialis $m$. (Figure 7).
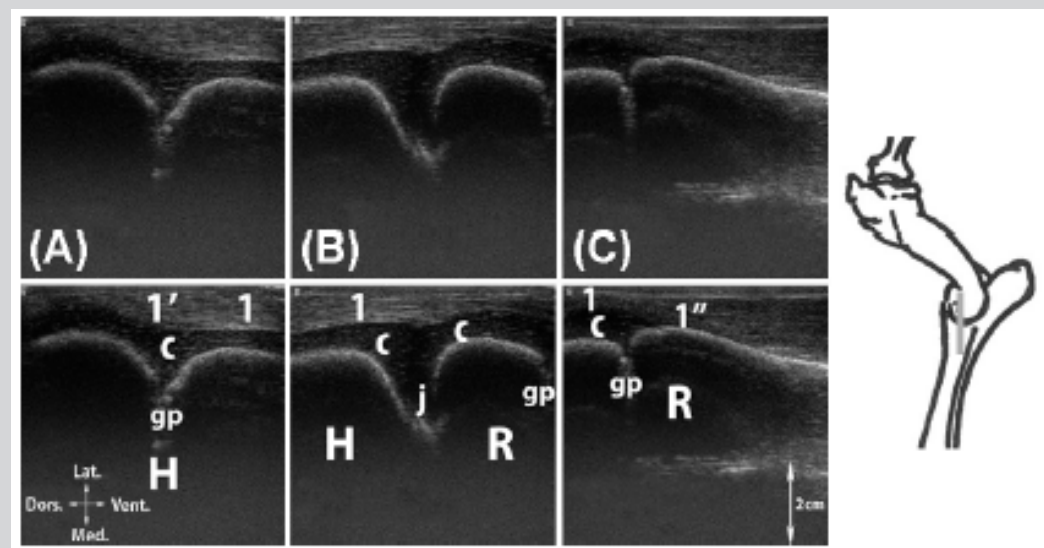

Figure 6: Longitudinal scan of the lateral collateral ligament (Lig. collaterale cubiti laterale). A, at the level of the humeral growth plate; $B$, at the level of the humeroradial joint; $C$, at the level of the radial growth plate.

Legend: H: humerus, R: radius, gp: cartilaginous growth plate, c: articular cartilage, j: humeroradial joint (Articulatio humeroradialis), 1: lateral collateral ligament (Lig. collaterale cubiti laterale), 1': proximal enthesis of the lateral collateral ligament, 1 "': distal enthesis of the lateral collateral ligament. 

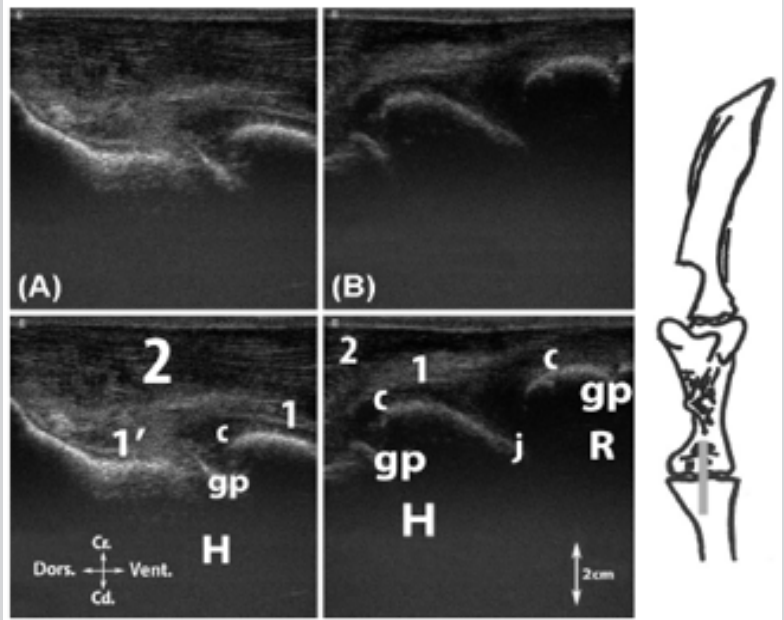

Figure 7: Longitudinal scan of the digital extensor $\mathrm{m}$. tendon enthesis.

$A$, at the level of the humeral growth plate; $B$, at the level of the humeroradial joint.

Legend: H: humerus, R: radius, l': medial and common (M. extensor digitorum communis) digital extensors mm. enthesis, c: articular cartilage, gp: cartilaginous growth plate, j: humeroradial joint, 1: medial or common digital extensor $\mathrm{m}$., 2: extensor carpi radialis $\mathrm{m}$.

\section{Carpal Region (Articulatio Carpi [39]) (Figure 8-13)}

It was possible to scan and describe seven regions of interest. The bone surface of the radius, the carpal bones (ossa carpi [39]) and the metacarpus bone, the joint spaces, the flexor and extensor tendons, the collateral carpal ligaments and the distal radial cartilaginous growth plate were identified. The operator was orientated by flexing the carpus and by palpating the different joints and bones. On the lateral aspect, the operator could also palpate the ulnar styloid process (processus styloideus [39]) and positioned the transducer parallel to the limb axis to visualise the lateral collateral carpal ligament (Lig. collaterale carpi laterale [39]), from its proximal to its distal insertion on the $4^{\text {th }}$ metacarpal bone (os metacarpale [39]). The proximal insertion was spread on the ulna and the radius. The distal part of the ulna and its wide cartilaginous growth plate were scanned. The probe had to slide dorsally in order to see the radiocarpal joint (articulatio radiocarpea [39]) aspect (Figure 8).

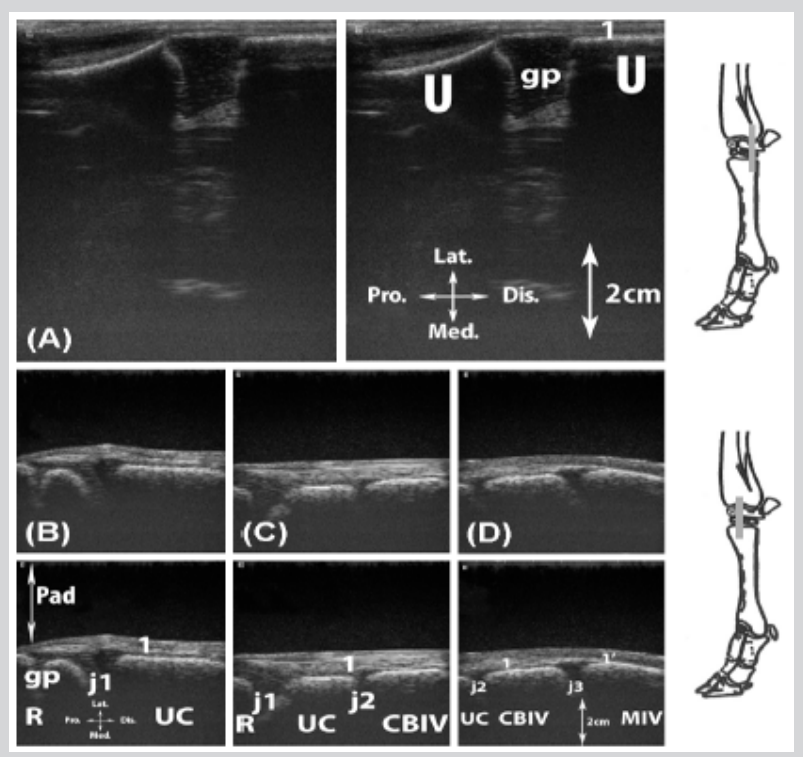

Figure 8: Longitudinal scan of the lateral collateral carpal ligament (Lig. collaterale carpi laterale).

A, palmar aspect, on the ulna; B, dorsal aspect, at the level of the radiocarpal joint; $C$, dorsal aspect, at the level of the midcarpal joint; D, dorsal aspect, at the level of the carpometacarpal joint.

Legend: CBIV: carpal bone IV (Os carpale IV [Os hamatum]), MIV: metacarpal bone (Os metacarpale) IV, Pad: standoff pad, R: radius, U: ulna, UC: ulnar carpal bone (Os carpi ulnare [Os triquetrum]), gp: cartilaginous growth plate, j1: radiocarpal joint (Articulatio radiocarpea), j2: midcarpal joint (Articulatio mediocarpea), j3: carpometacarpal joint (Articulationes carpometacarpeae), 1: lateral collateral carpal ligament (Lig. collaterale carpi laterale), 1': lateral collateral carpal ligament distal enthesis. 
Next, the transducer was positioned perpendicularly and the intercarpal joint (articulationes intercarpeae [39]), formed by the intermediate (os carpi intermedium [os lunatum] [39]) and the ulnar carpal (os carpi ulnare [os triquetrum] [39]) bones, was visualized as was the medial, common and lateral digital extensor m. tendons that run laterally to the carpus (Figure 9).
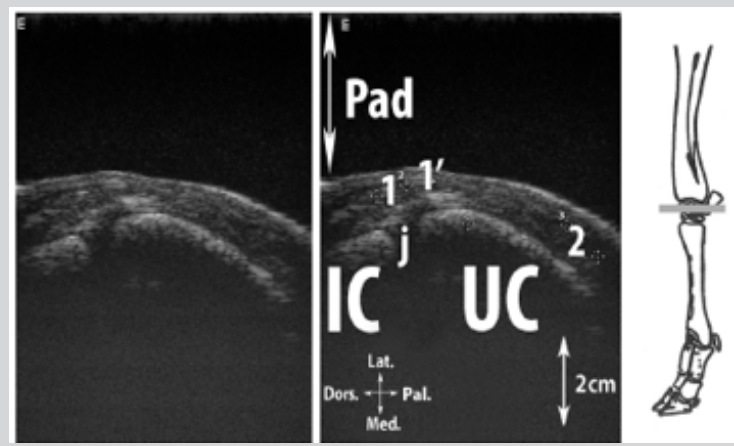

Figure 9: Transversal scan of the lateral aspect of the proximal carpal bones (Ossa carpi).

Legend: IC: intermediate carpal bone (Os carpi intermedium [Os lunatum]), Pad: stand-off pad, R: radius, UC: ulnar carpal bone, j: proximal intercarpal joint (Articulationes intercarpeae), 1: medial digital extensor tendon, l': common digital extensor tendon, 2: lateral digital extensor tendon.

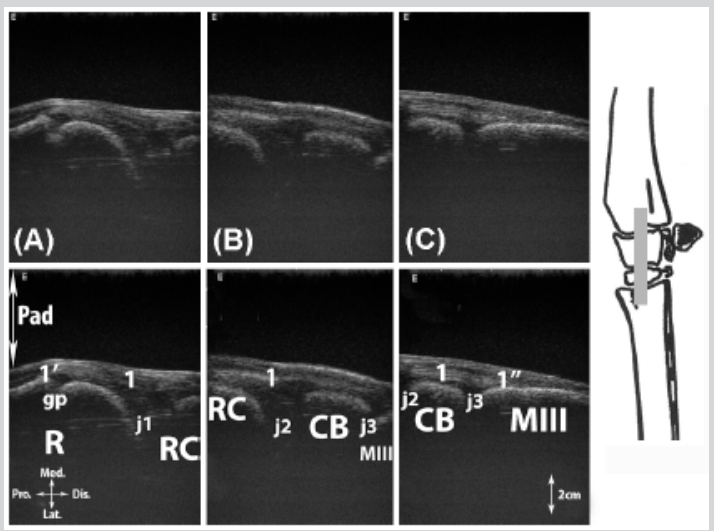

Figure 10: Longitudinal scan of the medial collateral carpal ligament (Lig. collaterale carpi mediale). A, at the level of the radiocarpal joint; B, at the level of the midcarpal joint; C, at the level of the carpometacarpal joint.

Legend: CB: carpal bones II (Os carpale II [Os trapezoideum]) and III (Os carpale III [Os capitatum]) fused, MIII: metacarpal bone III, Pad: stand-off pad, R: radius, RC: radial carpal bone (Os carpi radiale [Os scaphoideum]), gp: cartilaginous growth plate, j1: radiocarpal joint, j2: midcarpal joint, j3: carpometacarpal joint, 1: medial collateral carpal ligament, l': proximal enthesis of medial collateral carpal ligament, l'": distal enthesis of medial collateral carpal ligament.
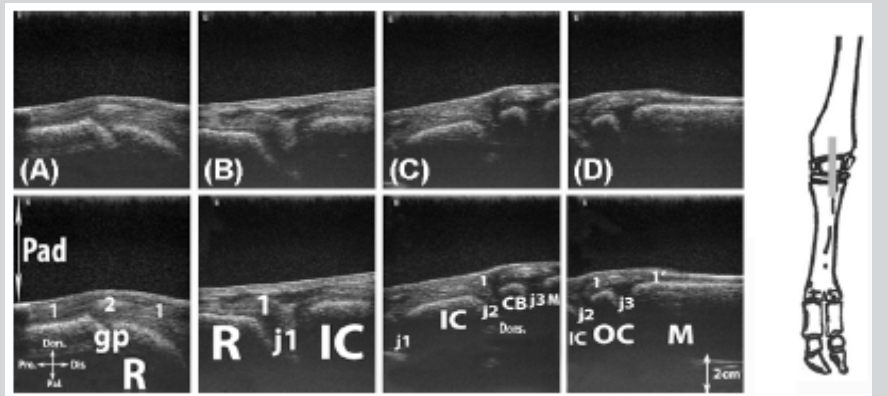

Figure 11: Longitudinal scan of the dorsal axial aspect of the carpus. A, at the level of the radial growth plate; B, at the level of the radiocarpal joint; $C$, at the level of the midcarpal joint; $D$, at the level of the carpometacarpal joint.

Legend: CB: carpal bones II and III fused, IC: intermediate carpal bone, M: metacarpal bone, Pad: stand-off pad, R: radius, gp: cartilaginous growth plate, j1: radiocarpal joint, j2: midcarpal joint, j3: carpometacarpal joint, 1: extensor carpi radialis tendon, 1 ': enthesis of extensor carpi radialis, 2: crossing between extensor carpi radialis and extensor carpi obliquus tendons. 
On the medial side, the radial styloid process was palpated, and the transducer was applied parallel to the axis of the limb. The medial carpal collateral ligament (Lig. collaterale carpi mediale [39]) was assessed on the longitudinal plane from its proximal insertion on the radius to its distal insertion on the $3^{\text {rd }}$ metacarpal bone. The cartilaginous growth plate of the radius was imaged (Figure 10). The dorsal aspect of the carpus was assessed on the longitudinal and transverse view in order to scan the carpal extensor and the digital extensor tendons. The proximal and distal carpal bone row were scanned using the transverse view. The extensor carpi obliquus $\mathrm{m}$. tendon was visualized on cross section, dorsal to the distal radial cartilaginous growth plate, crossing palmary to the extensor carpi radialis $\mathrm{m}$. tendon. The latter could be followed up to its insertion on the metacarpal bone (Figure 11). On the transverse plane, the axial part showed the extensor carpi radialis tendon, the medial part showed the extensor carpi obliquus tendon and the lateral part showed the medial and common digital extensor tendon bundle (Figure 12). On the palmar aspect of the carpus, the landmark was located by the palpation of the accessory bone (os carpi accessorium [os pisiforme] [39]). The transducer was placed perpendicular to the axis of the limb. The tendinous structures of the superficial digital flexor tendon (M. flexor digitorum [digitalis] superficialis [39]), the deep digital flexor tendon (M. flexor digitorum (digitalis) profundus [39]), the flexor carpi radialis, the ulnaris lateralis and the flexor carpi ulnaris $\mathrm{m}$. tendons were depicted (Figure 13). The image presented of the proximal view was obtained using the mobile ultrasound machine (IME520 Vet of IMEDSYS ® unit equipped with a 7.5 MHz rectal linear transducer).
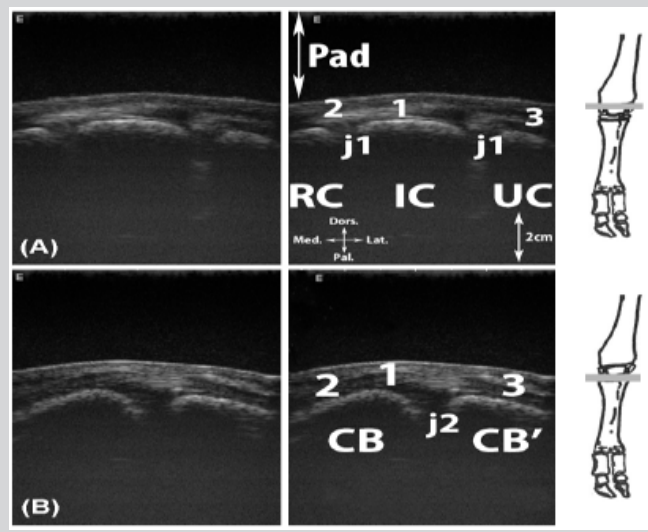

Figure 12: Transversal scan of the intercarpal joints. A, proximal inter-carpal joints; $B$, distal inter-carpal joints.

Legend: CB: carpal bones II and III fused, CB': carpal bone IV (Os carpale IV [Os hamatum]), IC: intermediate carpal bone, Pad: stand-off pad, RC: radial carpal bone, UC: ulnar carpal bone, j1: proximal intercarpal joints, j2: distal intercarpal joints, 1: extensor carpi radialis tendon, 2: extensor carpi obliquus tendon, 3: medial and common digital extensor tendons.
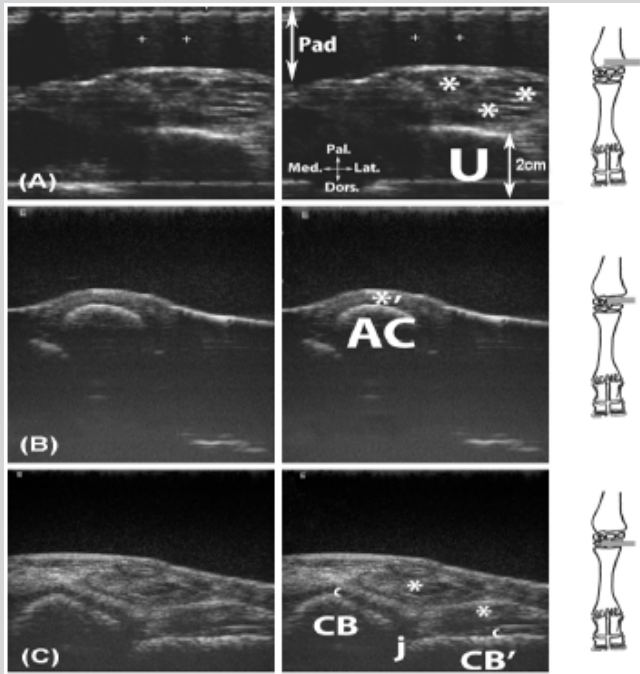

Figure 13: Transversal scan of the palmar aspect of the carpus. A, proximal aspect of the accessory carpal bone (from a portable unit equipped with a $7.5 \mathrm{MHz}$ transducer); B, on the accessory carpal bone; C, distal aspect of the accessory carpal bone.

Legend: AC: accessory carpal bone (Os carpi accessorium [Os pisiforme]), CB: carpal bones II and III fused, CB': carpal bone IV, j: distal intercarpal joint, Pad: stand-off pad, U: ulna, c: articular cartilage, ${ }^{*}$ : tendon structures in the superficial digital flexor tendon (M. flexor digitorum [digitalis] superficialis), the deep digital flexor (M. flexor digitorum [digitalis] profundus) tendon and the flexor carpi radialis regions, as well as the flexor carpi ulnaris and the ulnaris lateralis on the view proximal to the accessory carpal bone, ${ }^{*}$ : thickening of subcutaneous tissue at flexor carpi ulnaris and ulnaris lateralis $\mathrm{mm}$. enthesis region. 

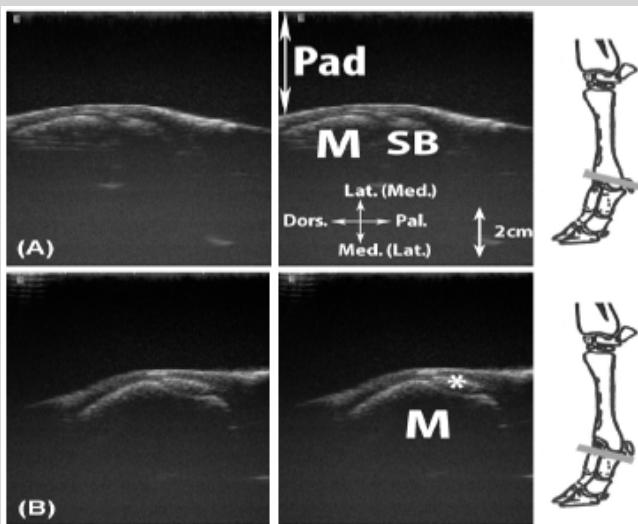

Figure 14: Transversal scan of the lateral and medial aspect of metacarpophalangeal joint (Articulationes metacarpophalangeae). A, proximal to the joint, at the level of the sesamoids; $B$, proximal to the joint, at the level of the metacarpal condyle.

Legend: M: metacarpal bone III or IV, Pad: stand-off pad, SB: proximal sesamoid bone (Ossa sesamoidea proximalia), *: ligament or tendinous structure (abaxial extensor branch of the interossei III or IV $\mathrm{mm}$. (Mm interossei III-IV) and collateral ligament region).

\section{Fetlock (Articulationes Metacarpophalangeae [39]) (Figure 14-18)}

Five regions of interest were scanned and described. The bone surface of the metacarpus, the phalanx and the proximal sesamoid bones (ossa sesamoidea proximalia [39]), the joint space, the distal metacarpus and phalangeal cartilaginous growth plates, the collateral ligaments, the extensor and flexor tendons, the interossei branches and the joint spaces were identified. The area was palpated to localize the proximal sesamoid bones and either the $3^{\text {rd }}$ metacarpal condyle on the medial side or the $4^{\text {th }}$ metacarpal condyle on the lateral side. The transducer was positioned oblique dorsoproximal to palmar distal and the region was studied (Figure 14).
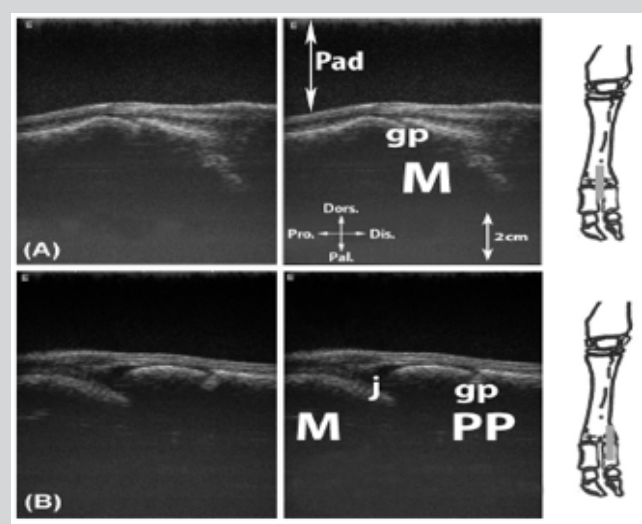

Figure 15: Longitudinal scan of the dorsal aspect of the metacarpophalangeal joint.

\section{A: axial aspect; B: abaxial aspect.}

Legend: M: metacarpal bone III or IV, Pad: stand-off pad, M: intercapital notch (Incisura intercapitalis), PP: proximal phalanx (Phalanx proximalis [Os compedale]), gp: cartilaginous growth plate, j: metacarpophalangeal joint.

The transducer was moved dorsal to the aspect of the fetlock and positioned parallel to the axis of the digits. The axial aspect showed the metacarpal intercondylar (incisura intercapitalis [39]) region and the distal metacarpal growth plate. The transducer was moved laterally or medially to study the metacarpophalangeal joints. The growth plate was depicted on the proximal aspect of the proximal phalanx (Figure 15). By rotating the transducers 90 degrees, a transverse view was obtained, and the digital extensor tendons were depicted as well as the axial branch of the interossei mm. (Mm interossei III-IV [39]). By moving the transducer more distally, the split of the common digital extensor was visualized as well as the axial branch of the interossei mm. (Figure 16). The palmar aspect of the fetlock was then studied. The dewclaw was the distal limit for the placement of the transducer. The proximal sesamoid bones were palpated, and the transducer was applied and positioned parallel to the metacarpal bone axis on the sesamoid bones in order to visualize the digital flexor tendons palmar to the interossei mm., which inserted on these sesamoid bones. The distal growth plate of the metacarpal bone was also depicted (Figure 17). The transducer was then rotated 90 degrees and moved proximally to reach the sesamoid bones. Proximal to the sesamoid bones, the interossei $\mathrm{mm}$ was studied and the digital flexor tendons were visualized. The four branches of the interossei $\mathrm{mm}$. that divide to attach on each proximal sesamoid bone were visualized and the axial bride ran in the intercondylar region. Palmar to the branches of the interossei $\mathrm{mm}$. and to the proximal sesamoid bones, the digital flexor tendon bundle was visualised (Figure 18). 


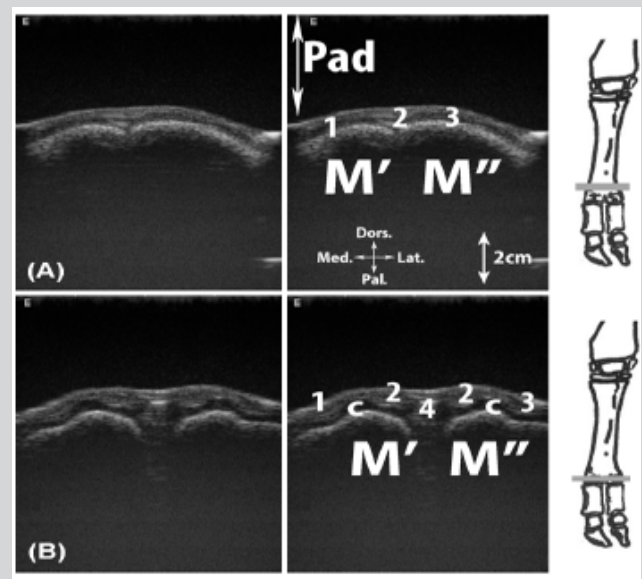

Figure 16: Transversal scan of the dorso-proximal aspect of the metacarpophalangeal joint.

A, proximal to the condyles; $B$, at the level of the condyles.

Legend: M': metacarpal bone III, M' : metacarpal bone IV, Pad: stand-off pad, c: articular cartilage, 1: medial digital extensor tendon, 2: common digital extensor tendon, 3: lateral digital extensor tendon, 4: axial extensor branch of the interossei $\mathrm{m}$.
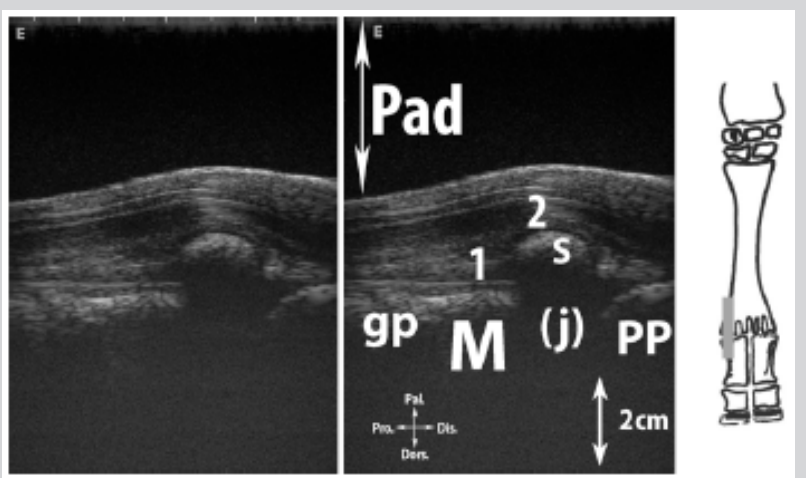

Figure 17: Longitudinal scan of the palmar aspect of the metacarpophalangeal joint.

Legend: Pad: stand-off pad, M: metacarpal bone III or IV, PP: proximal phalanx, S: proximal sesamoid bone, gP: cartilaginous growth plate, (j): localization of metacarpophalangeal joint not visualized because of the acoustic shadow from the sesamoid bone, 1: interossei III or IV branch, 2: digital flexor tendons.
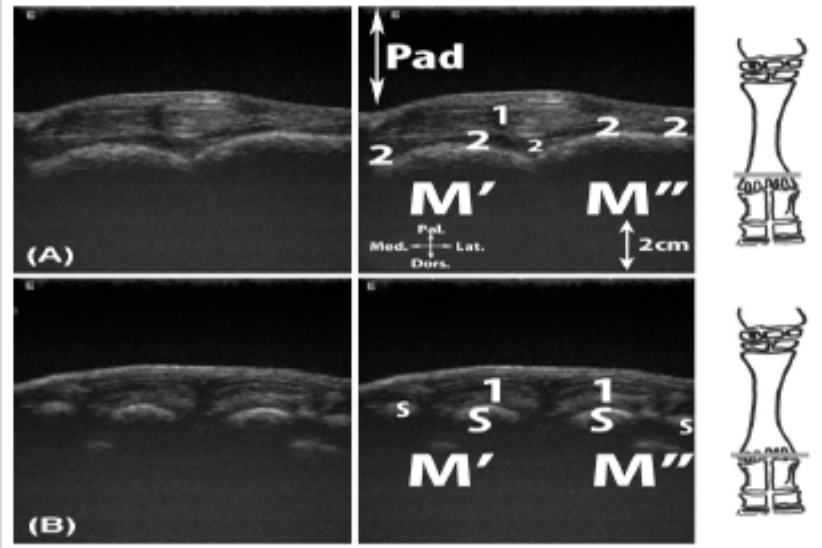

Figure 18: Transversal scan of the palmaro-proximal aspect of the metacarpophalangeal joint. A, proximal to the proximal sesamoid bones; B, at the level of the proximal sesamoid bone.

Legend: Pad: stand-off pad, M': metacarpal bone III, M"': metacarpal bone IV, S: proximal sesamoid bone, 1: digital flexor tendons, 2: interossei III and IV branches. 
Digits, pastern (articulationes interphalangeae proximales manus [39]) and coffin joints (articulationes interphalangeae distales manus [39]) (Figure 19-22).
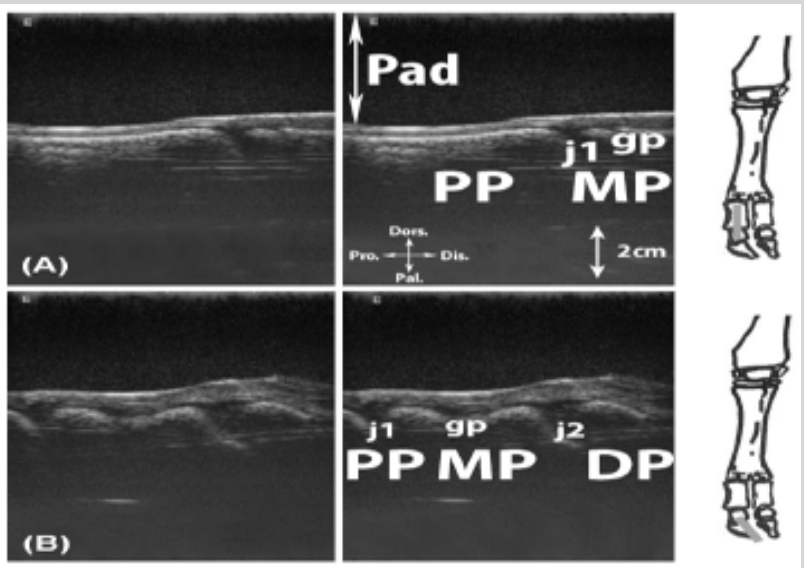

Figure 19: Longitudinal scan of the dorsal interdigital joints.

A, proximal interdigital joint; B, distal interdigital joint.

Legend: DP: distal phalanx (coffin bone) (Phalanx distalis), MP: middle phalanx (Phalanx media [Os coronale]), Pad: stand-off pad, PP: proximal phalanx (Phalanx proximalis [Os compedale]), gp: cartilaginous growth plate, j1: proximal interphalangeal joint, j2: distal interphalangeal joint.
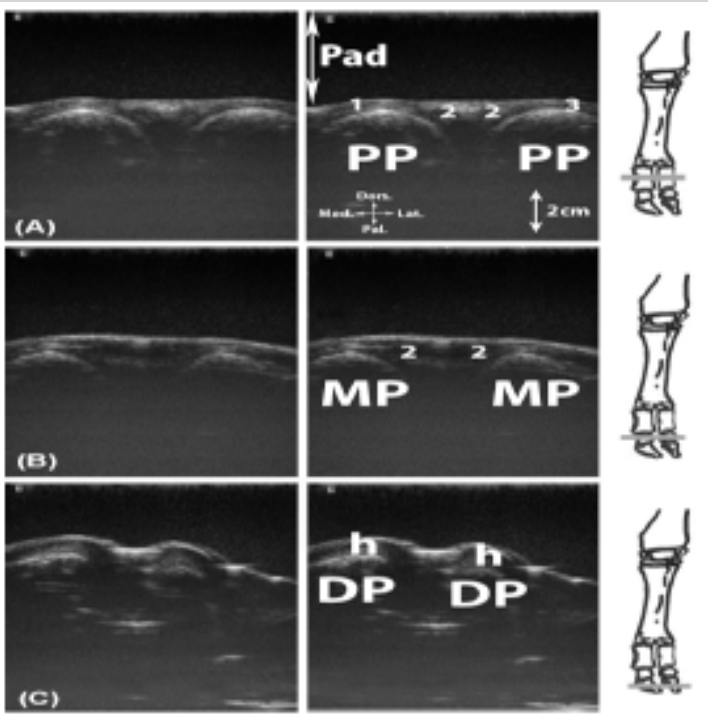

Figure 20: Transversal scan of the dorsal aspect of the digits.

A, at the level of the proximal phalanx; B, at the level of the middle phalanx; , at the level of the distal phalanx.

Legend: DP: distal phalanx (coffin bone), MP: middle phalanx, Pad: stand-off pad, PP: proximal phalanx, h: hoof capsule, 1: medial digital extensor tendon, 2: common digital extensor tendon, 3: lateral digital extensor tendon.

Four regions of interest were scanned and described. The bone surface of the phalanx, the extensor and the flexor tendons, and the joint spaces were identified. Starting from the longitudinal dorsal scan of the metacarpophalangeal joint, the transducer was moved distally, and each interphalangeal joint was assessed. To study the proximal interphalangeal joint (articulationes interphalangeae proximales manus [39]), the transducer was placed just proximal to the coronary band. The cartilaginous growth plate of the $2^{\text {nd }}$ phalanx (phalanx media [os coronale] [39]) was visible. For the second interdigital joint (articulationes interphalangeae distales manus [39]), the transducer was placed on the coronary band, with half of it on the claw (Figure 19). The transducer was then rotated
90 degrees to assess the digital extensor tendons at the level of the $1^{\text {st }}$ and $2^{\text {nd }}$ phalanges. The $3^{\text {rd }}$ phalanx (phalanx distalis [39]) was visualized through the hoof capsule (Figure 20). For the palmar aspect of the pastern, the views were obtained with the same orientation of the transducer as for the transversal scan of the proximopalmar aspect of the fetlock. The transducer was placed distal to the dewclaw and moved distally. The digital flexor tendons were assessed (Figure 21). The transducer was placed axial to the sole after cleaning it to visualize the distal interphalangeal joint as well as the insertion of the deep digital flexor tendon on the $3^{\text {rd }}$ phalanx (Figure 22). 


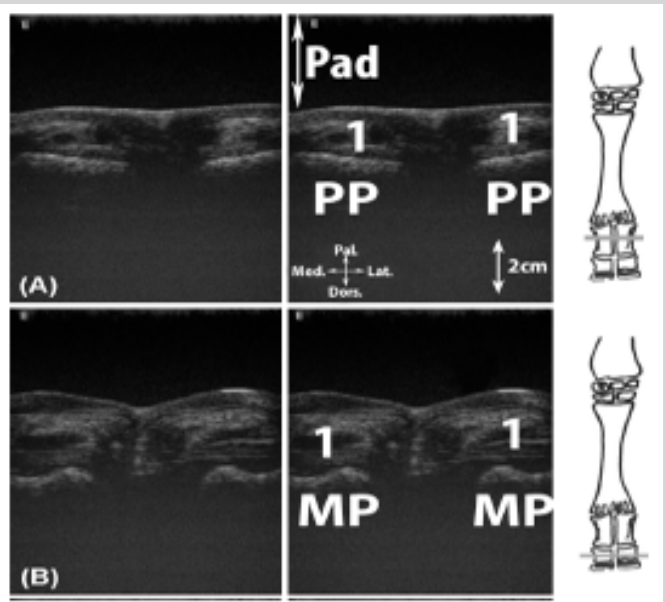

Figure 21: Transversal scan of palmar aspect of the digits. A, at the level of the proximal phalanx; B, at the level of the middle phalanx.

Legend: MP: middle phalanx, Pad: stand-off pad, PP: proximal phalanx, 1: digital flexor tendons.
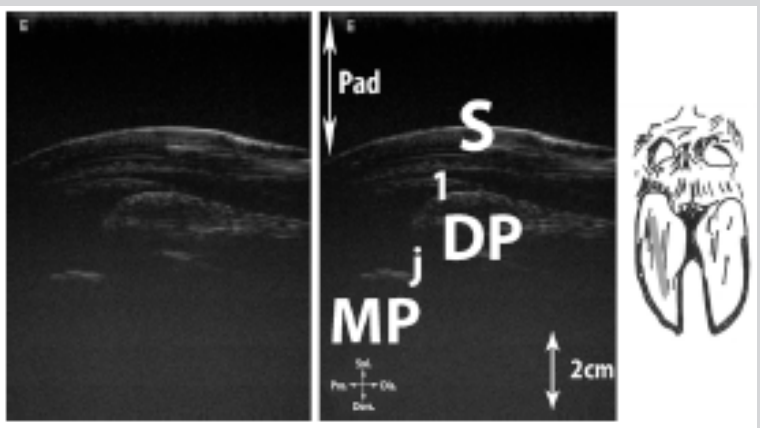

Figure 22: Longitudinal scan of solar aspect of the distal interphalangeal joint (Articulationes interphalangeae distales manus).

Legend: DP: distal phalanx (coffin bone), Pad: stand-off pad, MP: middle phalanx, S: sole, j: distal interphalangeal joint, 1: deep digital flexor tendon enthesis.

\section{DISCUSSION}

\section{Tissue Echogenicity and Limits of The Study}

As expected, the different tissues have a similar ultrasonographic appearance, as previously described in cattle $[17,18]$.

None of the joint recesses or tendon sheaths were confidently imaged, and most of the time only very small anechoic zones at the level of the joint space were identified. This is in accordance with previous descriptions $[5,11,17,22,24,28,29,33]$.

The joint capsules were not confidently found in any of the calves at any joint. However, it has been described and presented with a captioned picture in the healthy shoulder of a 4-week-old calf [11] and described with no captioned picture in the distal limb joints of 8-12 healthy calves [33]. We suggest that given the very thin structure, the breed variability and the operator variability, the joint capsule was not a consistent finding in 1- to 2-month-old healthy calves.

The muscle echogenicity was identical to that previously described $[17,40]$. The perimysium and the epimysium appear as hyperechoic conjunctive tissue. On the longitudinal view, these structures appear as parallel hyperechoic lines, whereas on the transversal view, the epimysium appears as a hyperechoic line around the muscle belly and the epimysium creates small hyperechoic pinpoints.

From the carpus to the more distal region, most of the longitudinal views of the tendons were difficult to obtain. This could be explained by the small size of the structure, the similar echogenicity to the surrounding soft tissue and the tendency of tendons to roll under the transducer when pressure is applied. These were in accordance with previous reports $[17,28]$.

Since the study was conducted on cadavers, the vascular structures could not be described. One previous study presented schemes to explain how to place the probe for optimal images [17], but in general it can be challenging to understand how the images were obtained in the ultrasonographic studies. We are confident that even a non-radiologist specialist veterinarian would be able to obtain the images presented in this study based on our descriptions and schemes. This would provide a useful tool for any veterinarian in the field who must assess the forelimb joints of a 1- to 2-monthold Holstein calf.

\section{Shoulder or Scapulohumeral Joint}

In the English-language literature, the ultrasonographic images of the bovine shoulder were previously studied in adult cattle and calves of unknown breeds [11,17] and reported among 
the diagnostic tools used in a case of chondrosarcoma in an adult Simmental cow [31]. These images were obtained with either a 3.5to $7.5 \mathrm{MHz}$ linear or sectorial probe providing lower definition than the images herein. Like these studies, due to the anatomic position and the anatomic structures, only the lateral and cranial aspect of the shoulder could be scanned. We are confident that having sutured the medial part of the shoulder to mimic the physiologic skin tautness was an appropriate technique to obtain suitable images because it was successfully done in a previous study [11].

All the different structures previously described were found. However, to our knowledge the present study is the first to present the images of the ossification centers of the greater and lesser tubercle.

The transverse scan of the scapular spine was previously described as the plane of choice to be oriented in this region [17] and presented in a 4-week-old calf [11]. In addition, a longitudinal view of this area was described but without an image [17]. However, we did not find any indication to present the longitudinal view. The transverse and longitudinal scan of the infraspinatus $m$. tendon as well as the biceps brachii $\mathrm{m}$. tendon have been described as the plane of choice [17] but no physiologic images [11] have been presented in calves. To our knowledge, this study is the first to present the captioned image of these regions.

The bursa of the infraspinatus tendon localized at its distal insertion was not identified, which is in accordance with the previous report [11]. The subtendinous recessus of the biceps tendon was not identified on the longitudinal or transversal view. This is in accordance with the previous report [11].

\section{Elbow Joint}

Like the shoulder, only the lateral and cranial part of the elbow was scanned. Even though the medial view is mentioned in the literature [17] we believe that it is not an easy view to obtain in calves. First, the closeness of the joint with the thorax made this approach difficult. Second, the relative bony composition of this area required the use of a stand-off pad, not an easy tool to use in a narrow area. However, if the calf is restrained in the lateral position with the limb extended in abduction, this might be feasible. To conclude, we believe that if the joint presents a distension, the lateral view would be enough to assess the region. No caudal view of the joint could be obtained due to the presence of the olecranon tuber The lateral approach has been presented in an adult Simmental cow [17] and in a case of arthritis in a 1-week-old Simmental calf [3]. The cranial approach has only been presented in an arthritis case in a 4-week-old Simmental calf [17]. These images were produced with a $7.5 \mathrm{MHz}$ linear transducer. Once again, our study is the first, to our knowledge, to present two high-definition views in healthy 1- to 2-month-old Holstein calves.

\section{Carpal Region or Antebrachiocarpal, Midcarpal and Carpometacarpal Joints}

The carpal region of cattle has been described and imaged in healthy adult Holtein-Friesen and Simmental cows [28], healthy 8to 9-month-old Simmental bull calves [28], a case of arthritis in a 1-week-old Highland calf [41], a case of bursitis in an adult HolsteinFriesen cow [32], and a case of arthritis of a 1-week-old Simmental and 5-month-old Brown Swiss calves [3]. These images were obtained with a 5 to $7.5 \mathrm{MHz}$ linear transducer. Our study is the first that describes and presents good-quality images on 1 to 2-monthold Holstein calves. As mentioned in previous studies $[17,28]$ for imaging from this region to the more distal regions, a stand-off pad was required to generate good-quality images. Indeed, the bony composition of these areas prevents adequate contact between the skin and the transducer.

This study is the first to present the cartilaginous growth plate of the ulna as shown on the longitudinal scan of the lateral collateral carpal ligament. Only the proximal part of the lateral collateral ligament had been presented previously [28] while the present study provides more images. Unlike the adult specimen, the longitudinal views of the digital extensor tendons were not confidently obtained. The tendons could not be stabilized behind the transducer due to their small diameters. Based on this finding, we would recommend assessment of these tendons using a transversal view. The tendon sheaths of the medial, common and lateral digital extensor were not visible. With this approach, the collateral ligament was not easily assessed, and the previous longitudinal view would be preferred.

The longitudinal scan of the dorsal axial aspect of the carpus was presented and described as the plane of choice in adult cattle $[17,28]$. However, this study is the first to present the images from the transversal views of the proximal and distal carpal rows. The radial carpus extensor tendon sheath was not visible.

On the palmar approach, the accessory bone was so prominent that even with the stand-off pad, the contact was insufficient. This area would benefit from further studies.

The palmar part of the carpus had been described in a longitudinal view [17], but we were not able to obtain any useful images. On the transversal views, we did not find the muscular part of the previously described superficial and deep digital flexor tendons [17]. Even with the use of the stand-off pad, the contact of the probe with the proximal aspect of the accessory bone was not ideal.

\section{Fetlock or Metacarpophalangeal Joint}

The palmar-plantar aspect of the distal limb of cattle has been presented in detail in mid-canon in previous articles [5,17,29,] and recently in 8- to 12-month-old Nellore and Girolando calves [33]. The pathological views have also been described in several articles $[4,17,25]$ and a few studies present the dorsal part of this region [17]. None of them specifically focus on the metacarpophalangeal joint. To our knowledge, our study is the first that has described this joint and presented the different views that could be examined. On the metacarpophalangeal joint views, the digital extensor tendons were not easily assessed on the longitudinal view, as they cannot be stabilized under transducer pressure, and the transversal views were preferred. This contrasted with the previous description in calves up to 8 months old; this difference could be explained by the smaller size of our younger specimens [33]. Neither the tendinous bursa of the lateral and medial extensor ligament nor the tendon sheath of the common digital extensor could be visualized. On the transversal aspect of the lateral and medial sides of the joint, the abaxial branches of the interossei mm were not easily assessed. The branches were thin and wide, making them difficult to distinguish from the subcutaneous tissues and the collateral ligaments. On the palmar aspect, the metacarpophalangeal joint was not assessable because of the bony nature of the sesamoid bone, which created an acoustic shadow. The digital sheaths of the digital flexor tendons were not visualized. This was in accordance with the previous description where it was inconstantly seen in adult cattle [5] and not seen in calves up to 8 months old [33]. Neither the manica flexoria or the palmar annular ligament could be distinguished. 
This was likely due to the small size of the structure. In addition, their presence was mentioned in a previous paper [17] but was neither depicted nor described $[5,17,33]$.

\section{Digits, Pastern or Proximal Interphalangeal Joints and Coffin or Distal Interphalangeal Joint}

Some of the articles that described the fetlock included a description and presented images of the interphalangeal joint $[5,17,33]$ as well as several pathological images [4]. The ultrasonographic description of the solar aspect of the limb has been described in adult cattle $[27,30]$.

Similarly, to previous descriptions in calves, the synovial pouches of the interphalangeal joints were not seen [33]. Comparably to the metacarpophalangeal joint, the extensor tendons could not be stabilized under the transducer pressure and were not distinguished from the subcutaneous tissue. This contrasted with the finding on calves up to 8 months old, which could be explained by the smaller structure of our younger specimens [33]. This made the assessment of the insertion on the extensor process of the $3^{\text {rd }}$ phalanx challenging. To assess the tendons, the transversal views were preferred; however, neither the tendon sheath nor the sub tendinous bursa were visualized. The present study is the first to present these transversal views. On the palmar aspect, we were not able to depict the area where the superficial digital flexor tendon separates from the deep digital flexor tendon to insert on the $2^{\text {nd }}$ phalanx, but no previous study discussed whether this view could be visualized. On the metacarpophalangeal level, the digital sheath was not visible. The solar approach has been described to be useful in the assessment of the sole thickness in adult cattle $[27,30]$ and the distal sesamoid bone could be visualized [27]. However, in the present study, the distal sesamoid bone could not be imaged because it was not yet ossified. This made the distal interphalangeal joint assessable; however, it was not possible to differentiate between the anechoic areas due to the cartilaginous composition of the navicular bone and the joint recess [41].

\section{CONCLUSION}

In this study, the ultrasonographic aspects of each joint of the forelimb of healthy 1 to 2-month-old Holstein calves were successfully described. Many of the views assessed have never been presented in calves within this age range and some have never been described in either adult or young cattle.

We provide herein a step-by-step description for transducer placement. We are confident that this study can serve as basic reference data for further ultrasonographic studies of the forelimb in 1 to 2-month-old calves. It can also serve as a guide for the veterinarian practitioner. In our initial study, all images were also acquired with a portable unit equipped with a $7.5 \mathrm{MHz}$ transducer and all were usable. Since most veterinarians in the field possess the same type of portable unit for gynecologic purposes, it is conceivable to use it to assess calves on the farm.

None of the previous studies presented images with a $13 \mathrm{MHz}$ probe, which provides superior definition. In that regard, this study is unique and provides very detailed images.

The main limitation of the study was the lack of measurements of the anatomical structures. However, because of the very low number of animals included in the study, it was not appropriate to perform any statistical analysis and therefore we would be unable to compare the size of the different structures studied. Another limitation was the lack of validation on live animals; however, the same findings should be demonstrated given that this has been noted in previous studies $[11,28,29]$. The vascular structures need to be described on live animals. In the future, it would be beneficial to study whether ultrasonographic aspects can be described for the grading of arthritis in the forelimb and could be used to triage calves to aid in deciding on treatment. Another potential aspect would be to investigate the presence of signs of early joint damage in septic neonates.

\section{ACKNOWLEDGEMENTS}

The authors wish to thank Dr. S. Buczinski, professor in the bovine ambulatory clinic at the University of Montreal, for having reviewed the initial thesis, Mr. P Paly from Imedsys, for having provided the IME520 Vet for the initial study, Dr. P Dowling, professor in Department of Veterinary Biomedical Sciences at the Western College of Veterinary Medicine (WCVM) for funding the image design and Ms. J. Deubner for designing the images, Mr. M Comte, assistant at the Oniris Department of Anatomy, for having performed the anatomical section and assisted in the dissections and Mr. S. Madec, Mr. C Raphael and Ms. D Rouleau, technicians in the Oniris Department of Diagnostic Imaging, for having taken the radiographs and performed the MRI, Pr. C Rummel at Giessen University for having translated the abstract in German for external communication. Dr. L Charnock, a $4^{\text {th }}$ year student in WCVM, G Davies, a $2^{\text {nd }}$ year student in WCVM, Dr. T Smith, LA surgery resident in WCVM, are thanked for having assisted in the writing of this article.

\section{REFERENCES}

1. Kidd JA, Lu KG, Frazer ML (2014) Atlas of equine ultrasonography. Wiley Blackwell, West Sussex, UK.

2. Ollivett TL, Buczinski S (2016) On-farm use of ultrasonography for bovine respiratory disease. Vet Clin North Am Food Anim Pract 32(1): 19-35.

3. Kofler J (1996) Arthrosonography-the use of diagnostic ultrasound in septic and traumatic arthritis in cattle - a retrospective study of 25 patients. The British Veterinary Journal 152(6): 683-698.

4. Heppelmann M, Rehage J, Kofler J, Starke A (2009) Ultrasonographic diagnosis of septic arthritis of the distal interphalangeal joint in cattle. Vet J 179(3): 407-416.

5. Tryon KA, Clark CR (1999) Ultrasonographic examination of the distal limb of cattle. Vet Clin North Am Food Anim Pract 15(2): 275-300.

6. Braun U (2016) Ultrasonographic examination of the reticulum, rumen, omasum, abomasum, and liver in calves. Vet Clin North Am Food Anim Pract 32(1): 85-107.

7. Mitchell KJ, Schwarzwald CC (2016) Echocardiography for the assessment of congenital heart defects in calves. Vet Clin North Am Food Anim Pract 32(1): 37-54.

8. Abhishek A, DePablo P, Buckley C, Raza K, Filer A (2013) SAT0080 Ankle synovitis and its prognostic implications in a very early arthritis cohort. Annuals of the Rheumatic Diseases 71: 497.

9. Backhaus M, Burmester GR, Sandrock D, Loreck D, Hess D, et al. (2002) Prospective two year follow up study comparing novel and conventional imaging procedures in patients with arthritic finger joints. Ann Rheum Dis 61(10): 895-904.

10. Scheel AK, Hermann KGA, Ohrndorf S, Werner C, Schirmer C, et al. (2006) Prospective 7 year follow up imaging study comparing radiography, ultrasonography and magnetic resonance imaging in rheumatoid arthritis finger joints. Ann Rheum Dis 65(5): 595-600.

11. Altenbrunner MB, Grubelnik M, Kofler J (2007) Ultrasonographic examination of important aspects of the bovine shoulder-physiological findings. Vet J 173(2): 317-324. 
12. Nuss K (2007) Ultrasonography of musculoskeletal disorders in cattle: A practical tool for veterinary surgeons. Vet J 173(2): 239-240.

13. Buczinski S (2016) We need more studies on the diagnostic and prognostic use of ultrasound in ruminants! Vet Clin North Am Food Anim Pract 32(1): 11-12

14. Anderson DE, Rings DM (2008) Current veterinary therapy: Food animal practice, fifth volume. Saunders Elsevier, St Louis, USA.

15. Davis UJ, Pajor EA, Schwartzkopf GK, Marti S, Dorin C, et al. (2017) Economic impacts of lameness in feedlot cattle. Translational Animal Science 1(4): 467-479.

16. Buczinski S (2009) Veterinary clinics of North America: food animal practice. 25(3): 11-12.

17. Kofler J (2009) Ultrasonography as a diagnostic aid in bovine musculoskeletal disorders. Veterinary Clinics of North America: Food Animal Practice 25(3): 687-731.

18. Buczinski S, Descôteau L (2009) Échographie des bovins. Point Vétérinaire, France.

19. Kofler J (1994) Neue Möglichkeiten zur Diagnostik der septischen Tendovaginitis der Fesselbeugesehnenscheide des Rindes mittels Sonographie-Therapie und Langzeitergebnisse. Deutsche Tierarztliche Wochenschrift 101: 215-222.

20. Kofler J (1997b) Ultrasonography in haematogenous septic arthritis, polyarthritis and osteomyelitis in calves. Wiener Tierarztliche Monatsschrift 84(5): 129-139.

21. Kofler J, Martinek B (2004) Ultrasonographic imaging of disorders of the carpal region in 42 cattle arthritis, tenosynovitis, precarpal hygroma, periarticular abscess. Tierärztliche Praxis. Ausgabe G, Grosstiere/ Nutztiere 32(2): 61-72.

22. Nogueira GM, Cattelan JW, Pereira WAB, Moraes PC, Duarte CA (2011) Caracterização ultrassonográfica das estruturas flexoras musculotendíneas e ligamentares da porção distal dos membros de novilhas cruzadas. Arquivo Brasileiro de Medicina Veterinária e Zootecnia 63(3): 600-608.

23. Nuss K (2003) Septische arthritis von schulter-Und hüftgelenk beim rind: diagnose und therapie. Schweizer Archiv Fur Tierheilkunde 145(19): 455-463.

24. Saule C, Nuss K, Köstlin R, Maierl J, Matis U (2005) Ultrasonographische Anatomie des Karpalgelenks des Rindes. Tierarztliche Praxis 33: 364372.

25. Kofler J (1996) Ultrasonographic imaging of pathology of the digital flexor tendon sheath in cattle. Vet Rec 139(2): 36-41.

26. Kofler J (1997a) Diagnostic ultrasound investigation in septic arthritis/ polyarthritis and osteomyelitis in calves. European Journal of Ultrasound 6: S5.

27. Kofler J, Kubber P, Henninger W (1999) Ultrasonographic imaging and thickness measurement of the sole horn and the underlying soft tissue layer in bovine claws. Vet J 157(3): 322-331.

28. Kofler J (2000) Ultrasonographic examination of the carpal region in cattle-normal appearance. Vet J 159(1): 85-96.

29. Kofler J, Edinger HK (1995) Diagnostic ultrasound imaging of soft tissues in the bovine distal limb. Veterinary Radiology \& Ultrasound 36(3): 246-252.

30. Laven LJ, Margerison JK, Laven RA (2012) Validation of a portable ultrasound machine for estimating sole thickness in dairy cattle in New Zealand. N Z Vet J 60(2): 123-128.

31. Martinek B, Bago Z, Flöck M, Hochsteiner W, Schilcher F, et al. (2006) Chondrosarcoma in a simmental cow: Clinical, ultrasonographic, radiographic and pathological findings. Vet J 72(1): 181-184.

32. Seyrek ID, Celimli N, Gorgul OS, Cecen G (2005) Comparison of clinical, ultrasonographic, and postoperative macroscopic findings in cows with bursitis. Vet Radiol Ultrasound 46(2): 143-145.

33. Gonçalves PVR, Silva LAFD, Silva LH, Costa APA, Bragato N, et al. (2014) Ultrasonography of the distal limbs in nellore and girolando calves 8 to 12 months of age. BMC Vet Res 10: 102.

34. Chapuis R (2014) Réalisation d'un atlas d'échographie des articulations saines du membre thoracique du veau. Thèse de doctorat vétérinaire, Faculté de Médecine, Nantes. Oniris: École Nationale Vétérinaire, Agroalimentaire etde l'Alimentation Nantes Atlantique.

35. Barone R (1986) Anatomie comparée des mammifères domestiques, tome 1, Ostéologie, $3^{\text {rd }}$ édn, Vigot, France.

36. Barone R (1996) Anatomie comparée des mammifères domestiques, tome 5, angiologie. $1^{\text {st }}$ édn, Vigot, France.

37. Barone R (2000) Anatomie comparée des mammifères domestiques, tome 2, arthrologie et myologie. $4^{\text {th }}$ édn, Vigot, France.

38. Barone R, Simoens P (2010) Anatomie comparée des mammifères domestiques, tome 7 , neurology ii, système nerveux périphérique, glandes endocrines, esthésiologie. 1ère édition, Vigot E, Lyon, France.

39. International Committee on Nomenclature VGA (2012) Nomina Anatomica Veterinaria. $5^{\text {th }}$ edn, Committee E, Hannover, Germany.

40. Busson J, Thelen P (2017) Échographie des muscles et des tendons. Journal de Radiologie 81: 317-327.

41. Munroe GA, Cauvin ER (1994) The use of arthroscopy in the treatment of septic arthritis in two highland calves. Br Vet J 150(5): 439-449. 